\title{
Effect of Thermal Deformation Regimes on the Austenite Growth Kinetics and Recrystallization of Medium Carbon Low-Alloyed Steel for Large-Sized Steam Turbine Rotors
}

\section{Solovyev I.V.1, Khimicheva E.E. ${ }^{1}$, Belikov S.V. ${ }^{1,2}$, and Kornienko O.Y. ${ }^{1}$}

${ }^{1}$ Federal State Autonomous Educational Institution of Higher Education «Ural Federal University named after the first President of Russia B.N.Yeltsin»

${ }^{2}$ M.N. Miheev Institute of Metal Physics of Ural Branch of Russian Academy of Sciences, $18 \mathrm{~S}$. Kovalevskaya Street, Yekaterinburg, Russia, 620137

\section{Abstract}

Effect of thermal deformation regimes on the austenite grain growth is studied in the article. The austenite grain growth curve based on the experimental data is constructed.

Corresponding Author:

Belikov S.V

s.v.belikov@urfu.ru

Received: 25 February 2019

Accepted: 9 April 2019

Published: 15 April 2019

Publishing services provided by Knowledge E

(c) Solovyev I.V. et al. This article is distributed under the terms of the Creative Commons

Attribution License, which permits unrestricted use and redistribution provided that the original author and source are credited.

Selection and Peer-review under the responsibility of The Ural school-seminar of metal scientists-young researchers Conference Committee.

\section{Introduction}

Medium carbon low-alloyed steels are widely used as hot-forged industrial parts. Knowledge of the alloys behavior during hot processing and operation, including recovery mechanisms, phase transformations, dynamic or static recrystallization, leads to the efficient industrial processing development of these materials. Behavior of medium carbon low alloy steels during hot deformation was considered in the works $[1 ; 2 ; 3 ; 4 ; 5]$. Of greatest interest is the problem solution of workpiece cracking during hot deformation. The processes of dynamic recovery and/or dynamic recrystallization occurring during hot deformation, in fact, prevent the initiation and microcracks spread, which are responsible for the premature metal failure $[6 ; 7]$.

The study of the hot deformation effect on the austenite structure formation has practical importance, because of the mechanical properties complex improvement is possible during thermal deformation processing by dislocations introducing and austenitic grain refining through dynamic recrystallization mechanisms. However, identification of the processes occurring during hot deformation is a rather complicated task, since the 
deformation is stopped at high temperatures, therefore the recovery and static recrystallization processes are occurred almost instantly [8].

In the manufacture of large-sized products, the deformation over the cross section of the ingot is unevenly distributed, and in some areas the deformation degree reaches a critical one, it leads to an austenitic grain growth to the original size. Some parts of the large-sized turbine rotor billet are subjected to high-temperature heating (over 1200 ${ }^{\circ}$ C) without subsequent deformation, therefore the austenite grain size increasing and mechanical properties decreasing are occurred. In this study, attention is paid to the austenite recrystallization processes during annealing at temperatures range of $900 .$. $1200{ }^{\circ} \mathrm{C}$, the thermal deformation treatment effect on the kinetics of growth and recrystallization of austenitic grain is investigated.

26CrNi3Mo2VA steel grade was used as study material. The samples were preannealed at temperatures range of $900 \ldots 1250{ }^{\circ} \mathrm{C}$ for 2.5 hours. When reheating, the samples were deformed according to different deformation modes.

TABLE 1: Chemical composition of 26CrNi3Mo2VA steel, \%.

\begin{tabular}{|c|c|c|c|c|c|c|c|c|c|c|}
\hline \multirow[t]{2}{*}{ Steel grade } & $C$ & $\mathrm{Si}$ & $\mathrm{Mn}$ & $\mathrm{Cr}$ & $\mathrm{Ni}$ & V & Mo & $\mathrm{S}$ & $\mathrm{P}$ & $\mathrm{Cu}$ \\
\hline & & & & & & & & \multicolumn{3}{|c|}{ не более } \\
\hline 26CrNi3Mo2VA & $\begin{array}{c}0,25- \\
0,30\end{array}$ & $\leq 0,040$ & $\begin{array}{c}0,30- \\
0,60\end{array}$ & $\begin{array}{c}1,30- \\
1,70\end{array}$ & $\begin{array}{l}3,40- \\
3,80\end{array}$ & $\begin{array}{c}0,12- \\
0,18\end{array}$ & $\begin{array}{c}0,50- \\
0,70\end{array}$ & 0,012 & 0,010 & 0,20 \\
\hline
\end{tabular}

Steel chemical composition is presented in Table 1

The austenite grain growth curve upon annealing in the temperature range under study based on the experimental data is presented on the fig. 1.

Austenite grain significant growth does not occur in the range of annealing temperatures $900 . . .1150^{\circ} \mathrm{C}$ and holding time 2.5 hours. The average austenite grain size is $18 \ldots 44$ $\mu \mathrm{m}$.

Austenitic grain significant growth starts at temperature of $1150{ }^{\circ} \mathrm{C}$ and reaches its maximum size at temperature of $1230^{\circ} \mathrm{C}$. The austenite grain size increasing is associated with the secondary recrystallization process, in which the growth of some grains occurs at the expense of other ones through the high-angle boundaries migration.

Thermal deformation treatment makes a significant contribution to the structure formation. Deformation at temperature $1230^{\circ} \mathrm{C}$ with a small deformation rate $\dot{\varepsilon}=0.1 \mathrm{~s}^{-1}$ and deformation degree $\varepsilon=0.29$ (Fig. 2 does not allow to obtain a fine-grained structure. Some of the small grains underwent dynamic recrystallization, while a larger number of grains have an elongated shape similar non-recrystallized grain. The average grain size is $75 \mu \mathrm{m}$. 


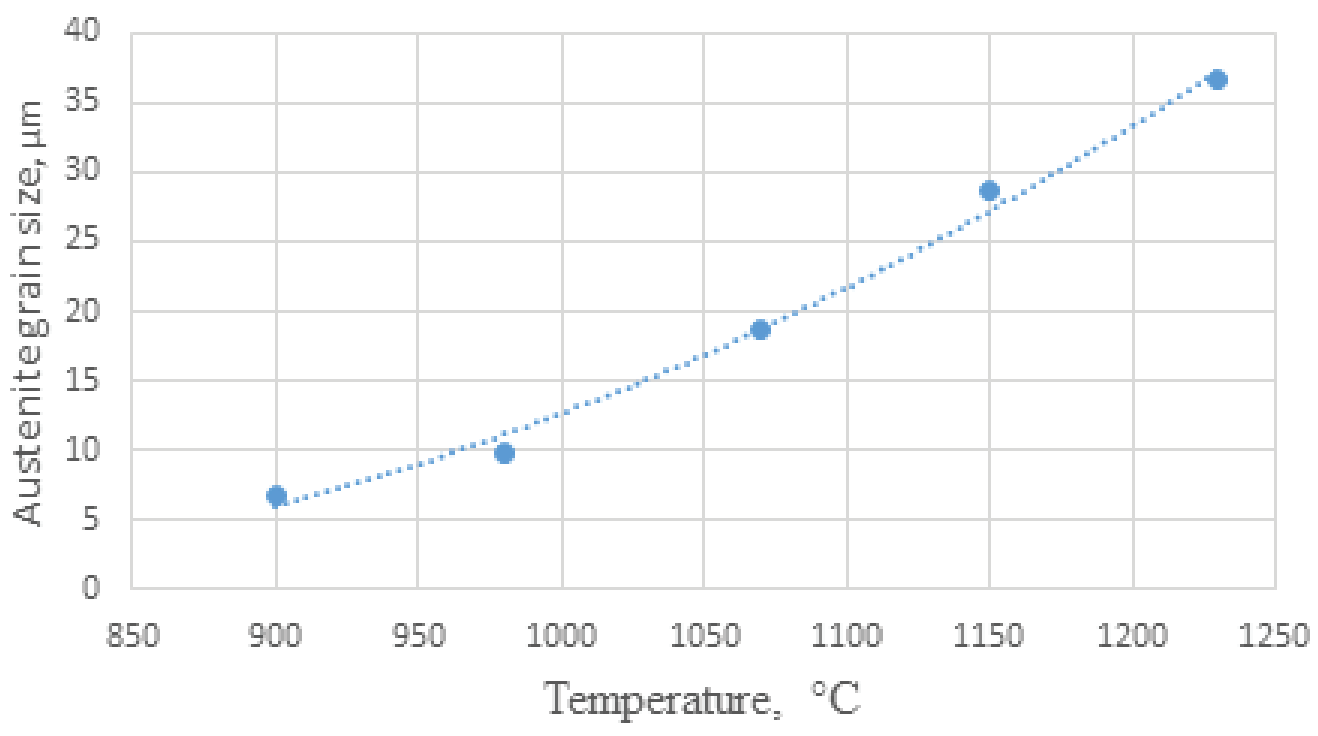

Figure 1: The annealing temperature effect on the austenite grain size.

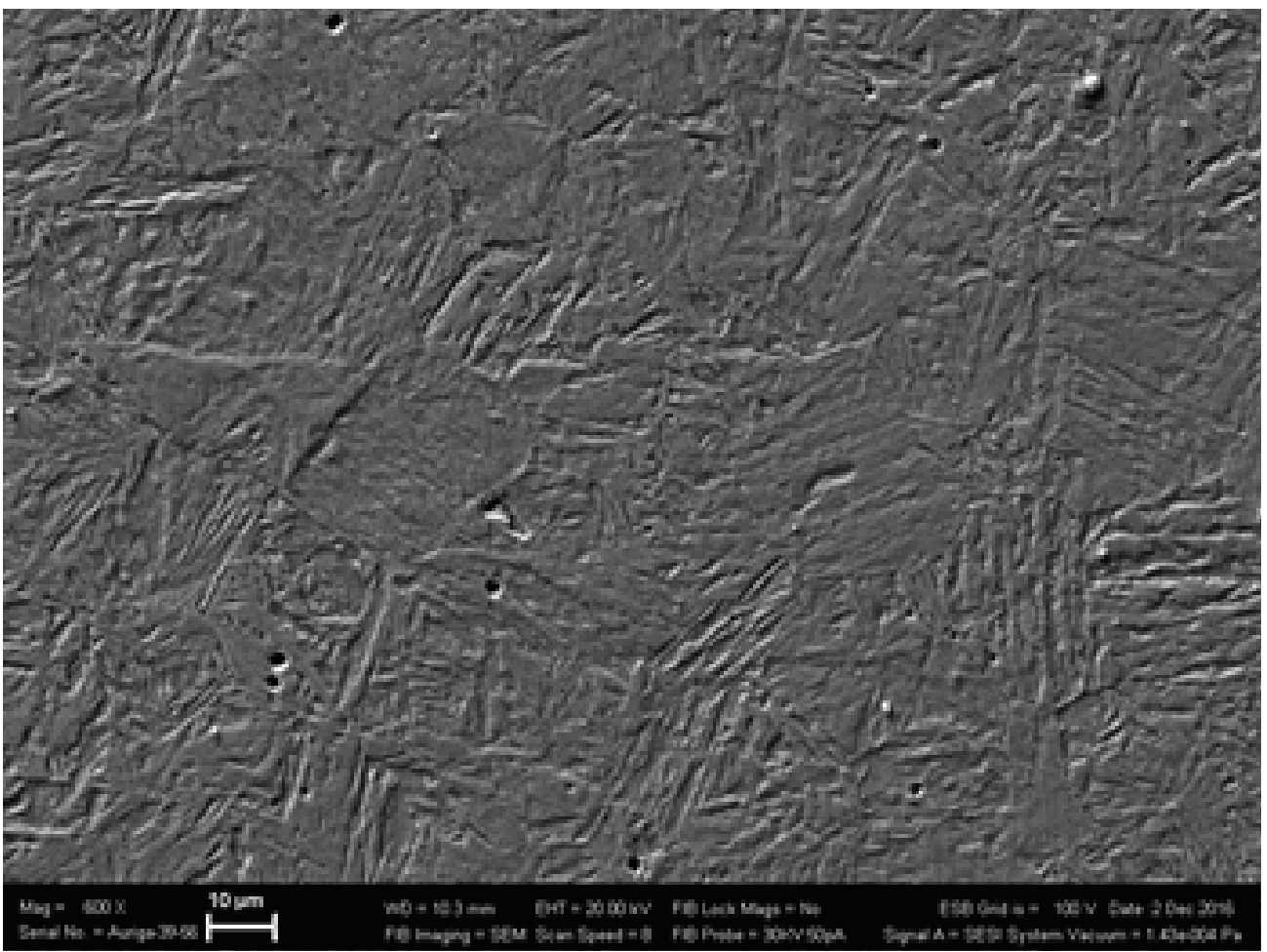

Figure 2: Lower bainite and martensite structure after annealing $900^{\circ} \mathrm{C}$.

A temperature decreasing up to $900{ }^{\circ} \mathrm{C}$, a deformation rate and degree increasing $\dot{\varepsilon}=50 \mathrm{~s}^{-1}$ and a $\varepsilon=1.3$ leads to a significant refinement of the austenite structure (Fig. 3). Dynamically recrystallized grains (left side) are relatively free of dislocations. The subgrain boundaries formation is occurred in deformed grains (the right part of the) similar the process of dynamic polygonization. The average grain size is $4 \mu \mathrm{m}$. 


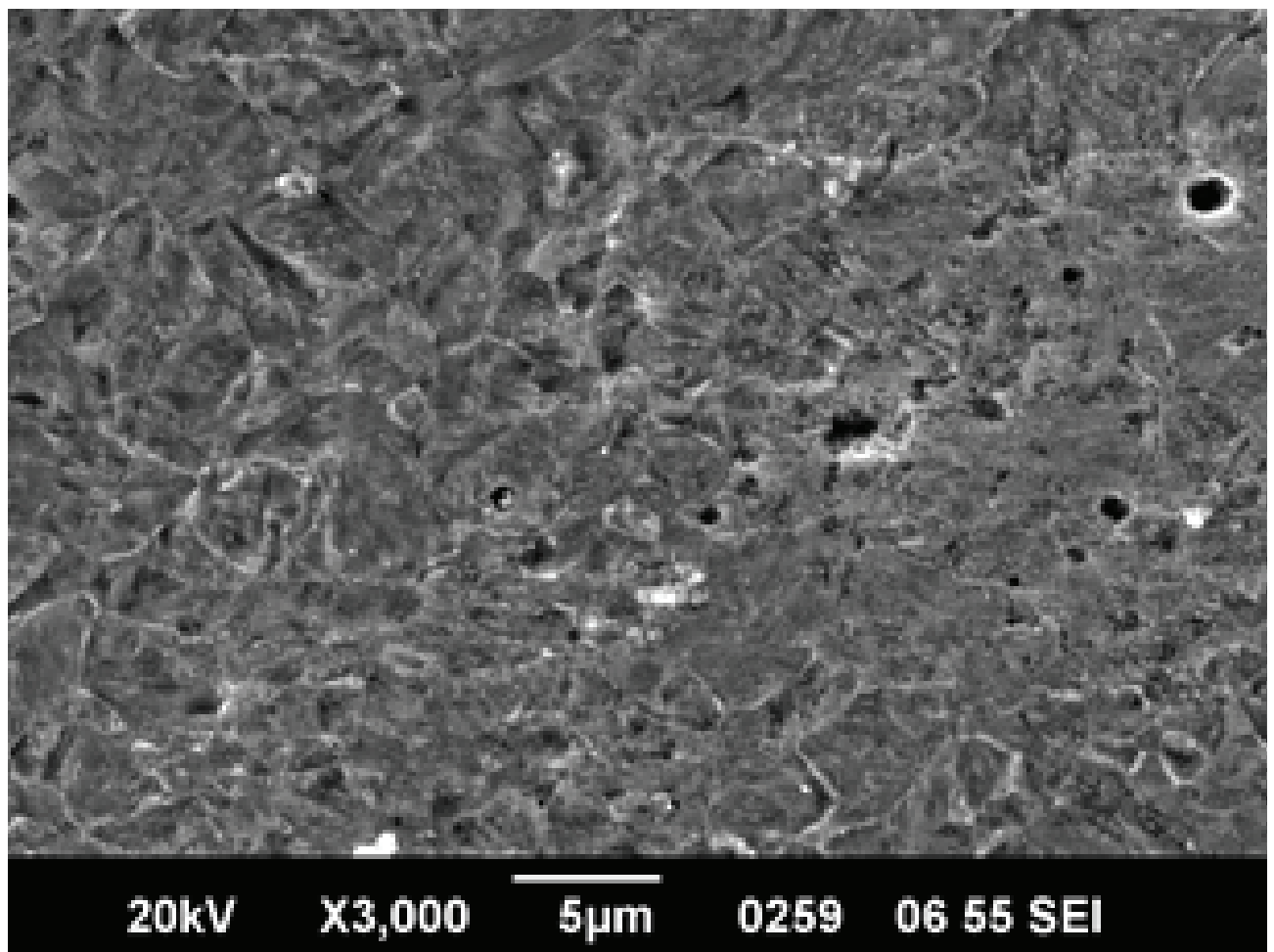

Figure 3: Microstructure after deformation.

Deformation at temperature $900^{\circ} \mathrm{C}$, deformation rate $\varepsilon=50 \mathrm{~s}^{-1}$, deformation degree $\varepsilon=0.33$, followed by annealing at a holding time 2.5 hours does not lead to significant grain growth (Fig. 4). The subgrain boundaries formed by thermal deformation are partially preserved. Static recrystallization does not proceed completely, since some of the grains retain elongated shape. The average grain size is $25 \mu \mathrm{m}$.

Curves of thermal deformation regimes effect on the austenite grain size are constructed based on the experimental data. The samples are pre- annealed at temperatures $900,1050,1250^{\circ} \mathrm{C}$ (Figures 5...7)

Analyzing the experiment results, it should be noted that steel with the initial smaller austenite grain is more prone to grinding in the deformation process. A deformation rate increasing above $\dot{\varepsilon}=0.1 \mathrm{~s}^{-1}$ and temperature decreasing contribute to the finer-grained structure formation. Grade deformation increasing also contributes to the grain grinding.

Along with dynamically recrystallized grains, a part of the deformed elongated grains have been not undergone recrystallization is retained in the structure. A subgrain structure divided by low-angle boundaries with different degrees of disorientation relative to each other is formed inside the grains. The temperature decreasing and the deformation rate increasing lead to the formation large austenite subgrain structure. The metal recovery is occurred at subsequent annealing i.e. point defects disappearance, and 


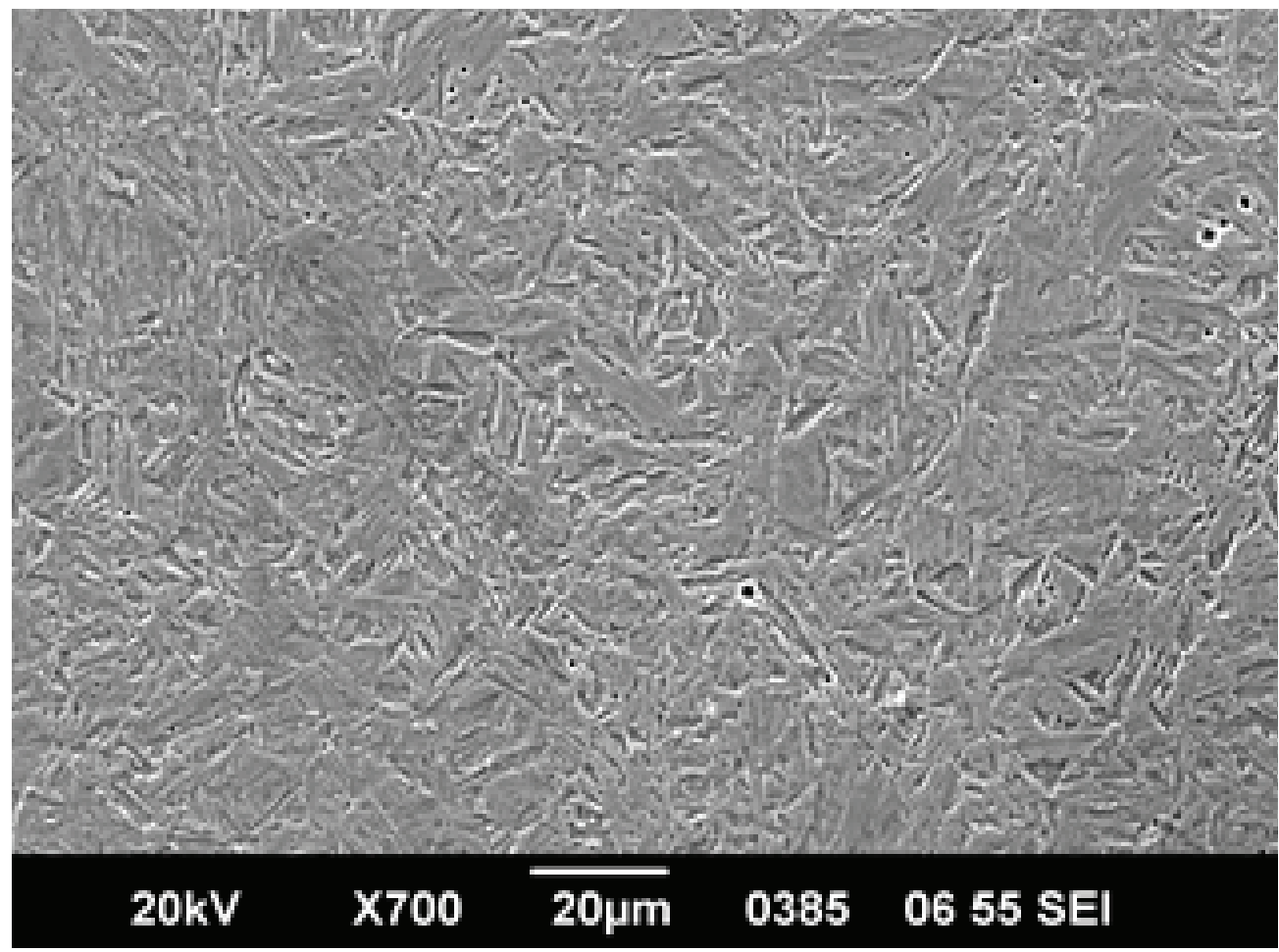

Figure 4: Martensitic structure after deformation and annealing.

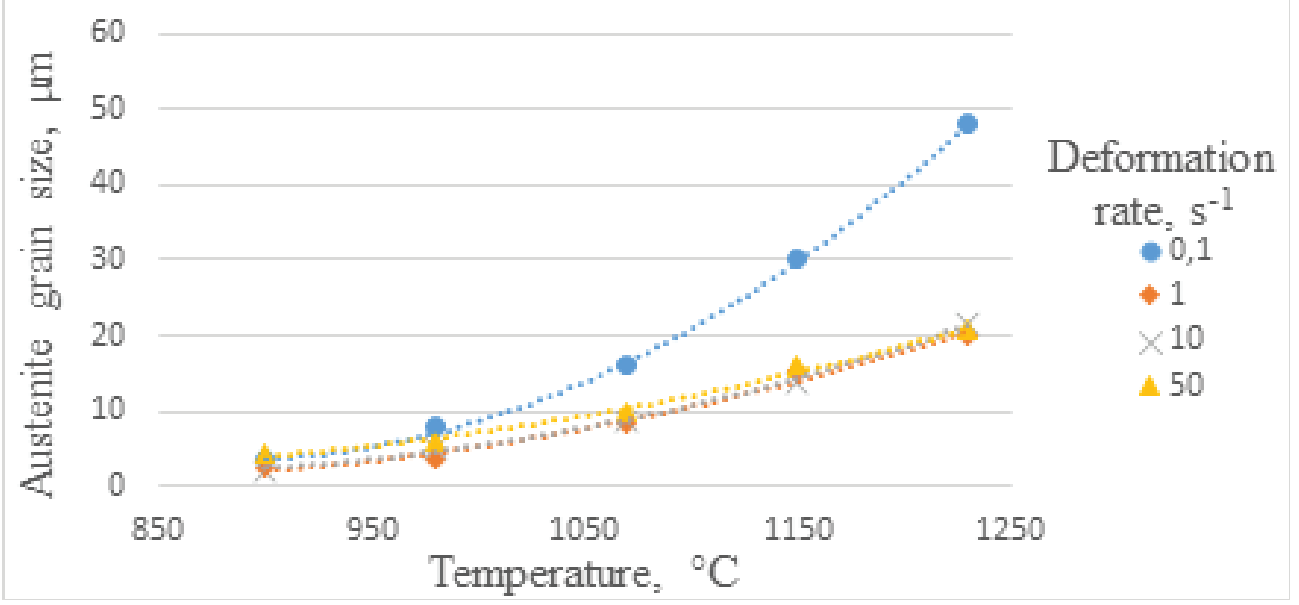

Figure 5: The effect of thermal deformation treatment on the grain size with pre-austenitization at $900{ }^{\circ} \mathrm{C}$.

polygonization. The formed subgrain structure has a positive effect on the formation of a fine-grained structure during subsequent annealing from deformation temperatures.

The work was carried out using the laboratory equipment "Structural methods of analysis and properties of materials and nanomaterials" of the Center of Ural Federal University. 


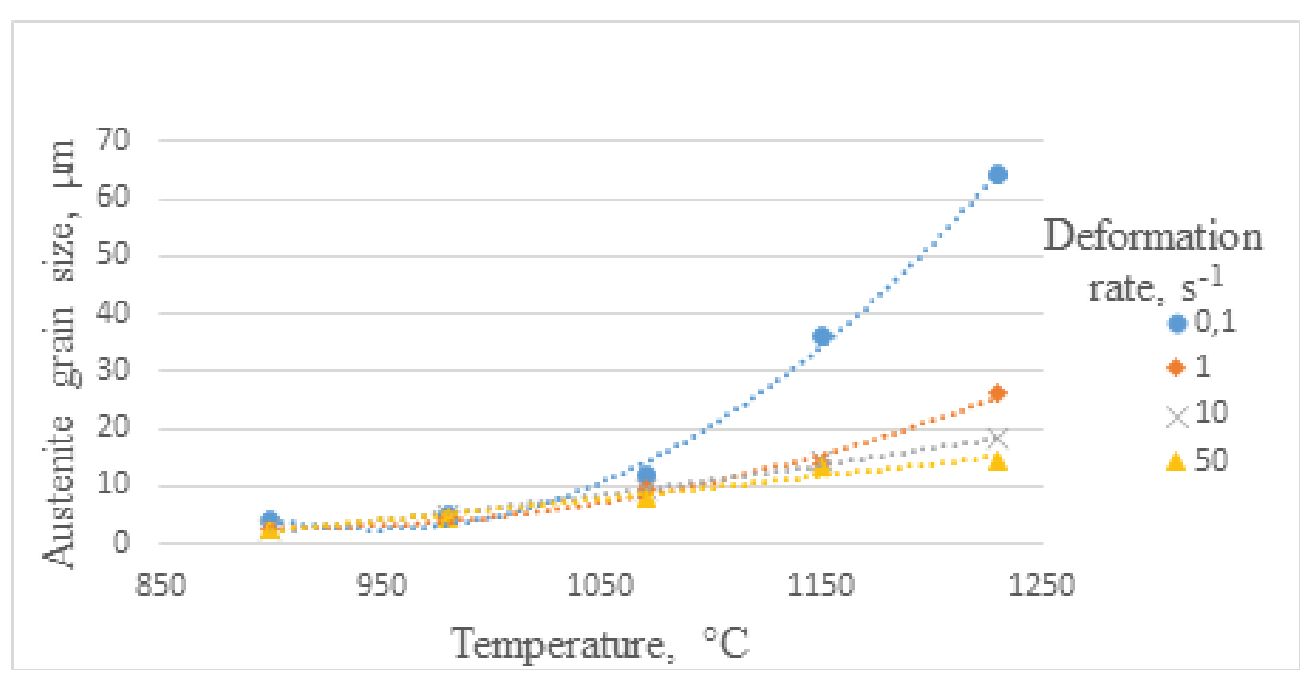

Figure 6: The effect of thermal deformation treatment on the grain size with pre-austenitization at $1050^{\circ} \mathrm{C}$.

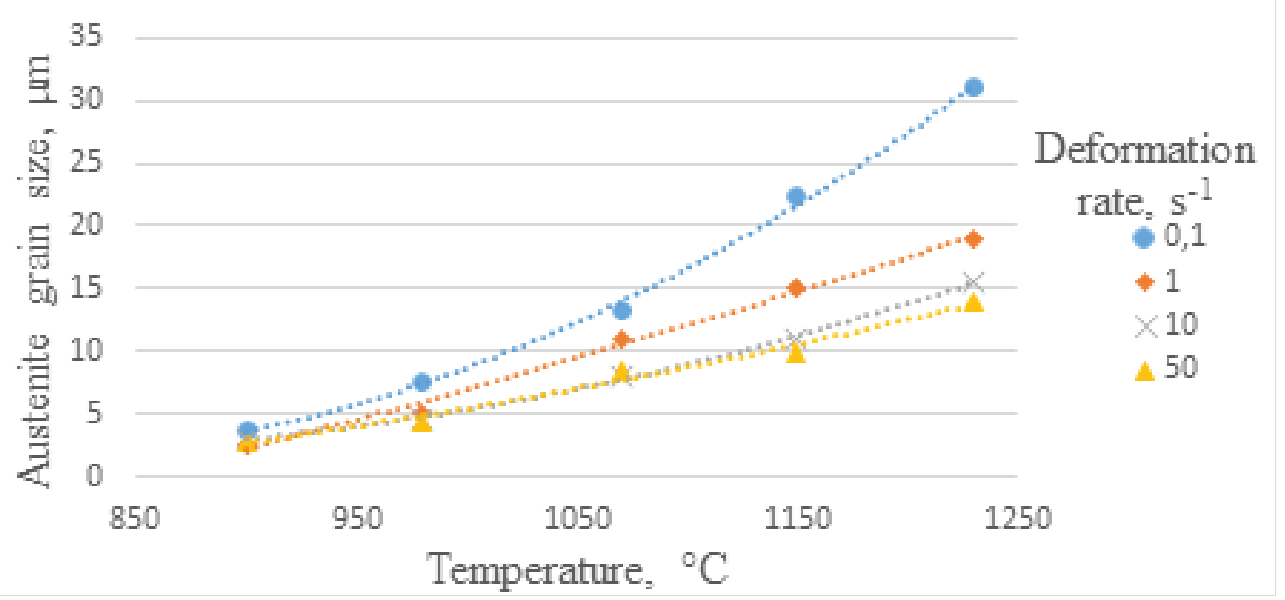

Figure 7: The effect of thermal deformation treatment on the grain size with pre-austenitization at $1250^{\circ} \mathrm{C}$.

\section{References}

[1] Lei X. Hot deformation behavior of medium carbon V-N microalloyed steel, Trans. Nonferrous Met. Soc. China. 2009. V. 19. pp. 1389-1394.

[2] Kim S. Modeling of AGS and recrystallized fraction of microalloyed medium carbon steel during hot deformation, Mater. Sci. Eng. A. 2003. V. 355. pp. 384-393.

[3] Mirzadeh $\mathrm{H}$. Hot deformation behavior of a medium carbon microalloyed steel, Mater. Sci. Eng. A. 2011. V. 28. pp. 3876-3882.

[4] in Y.C. Effects of temperatures on stress/strain distribution and microstructural evolution of deformed 42CrMo steel, Mater. Des. 2009. V. 30. pp. 908-913.

[5] Meysami M. Study on the behavior of medium carbon vanadium microalloyed steel by hot compression test, Mater. Sci. Eng. A. 2011. V. 28 pp. 3049- 3055. 
[6] Momeni K. Hot working behavior of 2205 austenite-ferrite duplex stainless steel characterized by constitutive equations and processing maps,Mater. Sci. Eng. A. 2011. V. 528. P. $1448-1454$.

[7] Prasad Y.V.R.K. Hot Working Guide: A Compendium of Processing Map, ASM International, Materials Park, OH.: 1997. pp. 545

[8] Gorelik S.S. Recrystallization metals and alloys, Moscow, 1978. 